\title{
One-Step Synthesis of Hollow Titanate (Sr/Ba) Ceramic Fibers for Detoxification of Nerve Agents
}

\author{
Satya R. Agarwal, ${ }^{1}$ Subramanian Sundarrajan, ${ }^{1}$ \\ Arunachalam Venkatesan, ${ }^{1}$ and Seeram Ramakrishna ${ }^{1,2,3}$ \\ ${ }^{1}$ Department of Mechanical Engineering, National University of Singapore (NUS), 2 Engineering Drive 3, Singapore 117584 \\ ${ }^{2}$ King Saud University, Riyadh 11451, Saudi Arabia \\ ${ }^{3}$ Intsitute of Materials Research and Engineering, Singapore 117602
}

Correspondence should be addressed to Subramanian Sundarrajan, mpesunda@nus.edu.sg

Received 31 January 2012; Accepted 14 August 2012

Academic Editor: John A. Capobianco

Copyright (c) 2012 Satya R. Agarwal et al. This is an open access article distributed under the Creative Commons Attribution License, which permits unrestricted use, distribution, and reproduction in any medium, provided the original work is properly cited.

Poly(vinyl pyrrolidone)(PVP)/(strontium/barium acetate)/titanium isopropoxide composite fibers were prepared by electrospinning technique via sol-gel process. Diameters of fibers prepared by calcinations of PVP composite fibers were $80-140 \mathrm{~nm}$ (solid) and 1.2-2.2 $\mu \mathrm{m}$ (hollow fibers prepared by core-shell method). These fibers were characterized using scanning electron microscope (SEM), X-ray diffraction (XRD), and transmission electron microscope (TEM) analytical techniques. XRD results showed better crystalline nature of the materials when calcined at higher temperatures. SEM and TEM results clearly showed the formation of hollow submicrometer tubes. The surface area of the samples determined by BET analysis indicated that hollow fibers have $\sim 20 \%$ higher surface area than solid fibers. The UV studies indicate better detoxification properties of the hollow fibers compared to solid fibers.

\section{Introduction}

Fabrication of ceramic fibers via electrospinning has recently drawn much interest owing to their simple nature of fabrication and versatile applications [1]. Due to their surfaceand size-dependant properties, ceramic nanofibers prove to be useful materials in several applications [2]. Ceramic nanomaterials provide better solutions than their bulk counterparts and could eventually be used in many applications such as biosensors, biomolecular machines, catalysis, solar cells, fuel cells, hydrogen storage, membranes, batteries, and tissue engineering, due to their unique properties [3]. Currently, the large-scale productions of such systems are uneconomical and controlling the size of the fibers is a challenge [4].

Strontium titanate (STO) has a perovskite structure at room temperature. At the lowest temperatures measured, it behaves as a paraelectric material, but it shows a ferroelectric phase transition with large dielectric constant of $\sim 104$ at temperatures much lower than room temperature [5].
It finds important applications in varistors, precision optics, as a diamond simulant and in advanced ceramics [6]. Szot et al., 2006 [7], reported the switching behavior is an intrinsic feature of naturally occurring dislocations in single crystals of a prototypical ternary oxide, $\mathrm{SrTiO}_{3}$. Yan et al., 2010 [8], recently reported the switching mechanism in $\mathrm{Ag} / \mathrm{SrTiO}_{3} / \mathrm{Pt}$ memory cells. In the case of barium titanate (BTO), it is a ferroelectric material, with piezoelectric properties [9]. These fibers have potential applications as ferroelectric transducers and show better performance than their thin films counterpart [10-12].

In the past few decades, chemical and biological warfare have grown tremendously owing to the rapid technological advances. These warfare methods possess great threats to the human race. Amongst the most hazardous agents areorganophosphorous agents, nerve agents, mustard agents and toxins such as chlorine and arsine. Current protective gear such as HAZMAT (Hazardous materials), JSLIST (Joint Service Lightweight Integrated Suit Technology), and BDO (Battle Dress Over) rely on activated carbon. These gears are 
heavy and retain the moisture content, making it unbearable to be worn after $8-10$ hrs [13].

In the present work, we report the synthesis of $\mathrm{SrTiO}_{3}$ and $\mathrm{BaTiO}_{3}$ nanofibers with different morphologies. These one-dimensional fibers show exciting results compared to thin films. The hollow fibers show promising results for use as chemical and biological warfare catalysts. These materials can be coated on the protective gear providing lightweight and comfortable solutions to the soldiers. We opted to choose these materials since they show excellent electrical properties and can also be used as chemical and biological sensors, data transfer, and real-time monitoring of the health conditions of a soldier during warfare. These materials can provide total integrated solutions for protective clothing. We are currently investigating these materials for applications in RRAM devices, ferroelectric transducers [1, $2,4,14]$. To the best of our knowledge, this is the first report for the fabrication of aligned and hollow strontium titanate nanofibers (by electrospinning). It is also the first report for detoxification studies using hollow fibers and their comparison with solid fibers.

\section{Methods}

2.1. Materials. (PVP; $\left.\mathrm{M}_{n}=51,300,000\right)$ was obtained from Sigma-Aldrich (Sigma-Aldrich Corp., St. Louis, MO, USA). Analytical grade strontium acetate, $\left(\mathrm{CH}_{3} \mathrm{CO}_{2}\right)_{2} \mathrm{Sr}$, of $>99.0 \%$ purity was obtained from Sigma-Aldrich (Germany). Analytical grade barium acetate, $\left(\mathrm{CH}_{3} \mathrm{CO}_{2}\right)_{2} \mathrm{Ba}$, of $>99.0 \%$ purity was obtained from Sigma-Aldrich (Germany). Ethanol was supplied by Lab-scan Asia Co. Ltd. (Thailand). Acetic acid, titanium isopropoxide $\left(\mathrm{C}_{12} \mathrm{H}_{28} \mathrm{O}_{4} \mathrm{Ti}\right)-97 \%$, trifluoroacetic acid (TFA), heptane (99\%), and mineral oil were obtained from Sigma-Aldrich (Germany); all the chemicals were used as obtained.

2.2. Fabrication of $(\mathrm{Sr} / \mathrm{Ba}) \mathrm{TiO}_{3}$ Nanofibers (Solid). Strontium/barium acetate was first dissolved in acetic acid in $1: 2$ ratio. The mix was stirred under a magnetic agitator for $1.5 \mathrm{~h}$. Then, $0.8 \mathrm{~mL}$ of TFA was added and stirred for another 15 mins. PVP solution was prepared by dissolving $0.2 \mathrm{~g}$ polymer in $3 \mathrm{~mL}$ ethanol. After $15 \mathrm{mins}$ of further stirring, $1.5 \mathrm{~mL}$ of titanium isopropoxide was added and, the solution was stirred for another $1.5 \mathrm{~h}$, after which a clear yellow-colored solution was obtained. This (PVP)/(strontium/barium acetate)/titanium isopropoxide composite sol was taken in a $3 \mathrm{~mL}$ capacity BentonDickenson clinical syringe attached with a $27 \mathrm{G}$ stainlesssteel needle $(0.4 \mathrm{~mm}$ needle diameter). An electric field of 14-16 kV (Gamma high-voltage power supply, Gamma highvoltage, FL) was applied between the needle and the ground (a rotating wheel at $2500 \mathrm{rpm}$ was used for collecting aligned fibers; a rotating drum at $300 \mathrm{rpm}$ was used for collecting random fibers) at a distance of $8 \mathrm{~cm}$. All experiments were conducted at room temperature with relative humidity $(50 \%-60 \%)$ condition having flow rate of $0.8 \mathrm{~mL} / \mathrm{h}$. After electrospinning, the as-spun (PVP)/(strontium/barium acetate)/titanium isopropoxide composite fibers were calcined for $3 \mathrm{~h}$ in air at different temperatures $\left(450^{\circ}-800^{\circ} \mathrm{C}\right)$

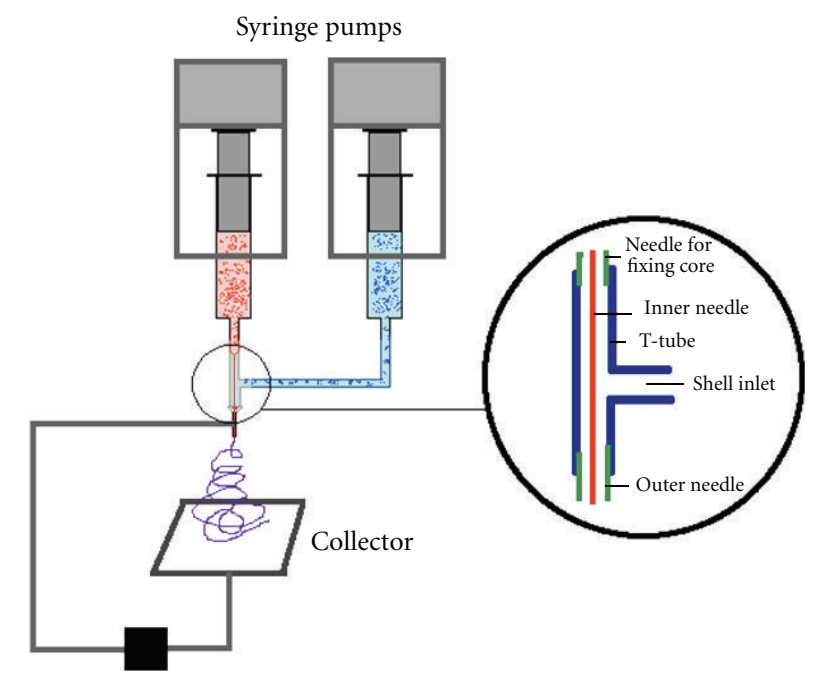

High-voltage power supply

FIGURE 1: Illustration of the core-shell setup for electrospinning hollow fibers.

at a heating rate of $3^{\circ} \mathrm{C} / \mathrm{min}$ in order to obtain pure $(\mathrm{Sr} / \mathrm{Ba}) \mathrm{TiO}_{3}$ nanofibers.

2.3. Fabrication of $(\mathrm{Sr} / \mathrm{Ba}) \mathrm{TiO}_{3}$ Microfibers (Hollow). Hollow $(\mathrm{Sr} / \mathrm{Ba}) \mathrm{TiO}_{3}$ fibers were prepared via core-shell electrospinning method. Mineral oil was used as core solution and the solution for shell was prepared by the method described above. Both core and shell solutions were loaded into two different plastic syringes of $3 \mathrm{~mL}$ each. The setup for the coreshell apparatus is shown in Figure 1.

The inner diameter of the needle used for the core solution is $0.4 \mathrm{~mm}$. The diameter of the outer needle is $1.27 \mathrm{~mm}$. An electric field of $12-14 \mathrm{kV}$ (Gamma highvoltage power supply, Gamma high-voltage, FL) was applied between the needle and the ground (aluminium foil) at a distance of $12 \mathrm{~cm}$. All the experiments were performed at room temperature with relative humidity (50-60\%) condition. The flow rates for core and shell solutions were set at $0.3 \mathrm{~mL} / \mathrm{h}$ and $0.8 \mathrm{~mL} / \mathrm{h}$, respectively. After electrospinning, the as-spun (PVP)/(strontium/bariumacetate)/titanium isopropoxide composite fibers were washed in heptane solution to remove the mineral oil (core). In order to obtain pure $(\mathrm{Sr} / \mathrm{Ba}) \mathrm{TiO}_{3}$ hollow fibers, the samples were calcined for $3 \mathrm{~h}$ in air at a temperature range of $450-800^{\circ} \mathrm{C}$ at a heating rate of $3^{\circ} \mathrm{C} / \mathrm{min}$.

\section{Characterization}

Surface morphology of $(\mathrm{Sr} / \mathrm{Ba}) \mathrm{TiO}_{3}$ fibers was characterized using a Quanta FEI (The Netherlands) SEM instrument operating at $10-15 \mathrm{kV}$. Goal coating of the samples for $100-$ 120 seconds was performed to increase the conductivity of the samples using a JEOL FRC 1200 fine coater (Jeol Ltd., Singapore) before taking SEM. ImageJ 1.29 (222 commands) (Java image processing software) was used to measure the average diameter of the fibers. At least 60 measurements were 


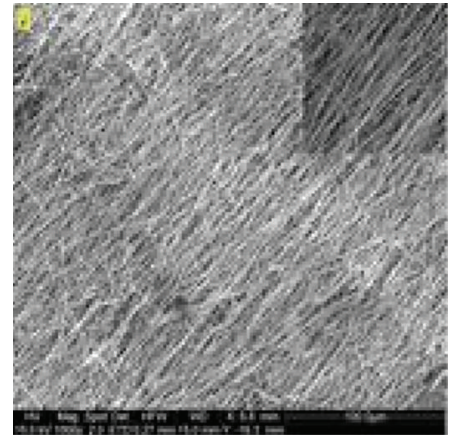

(a)

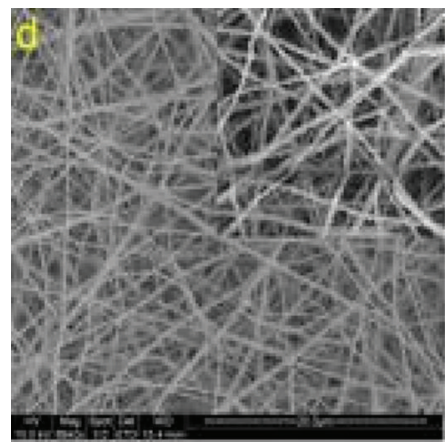

(d)

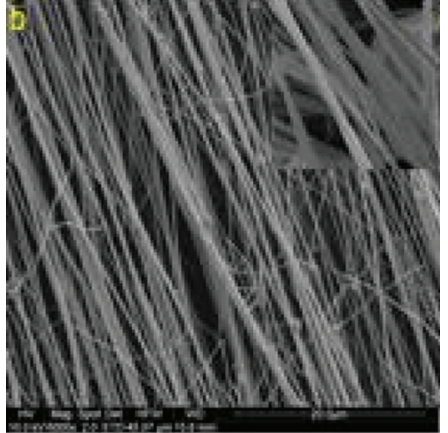

(b)

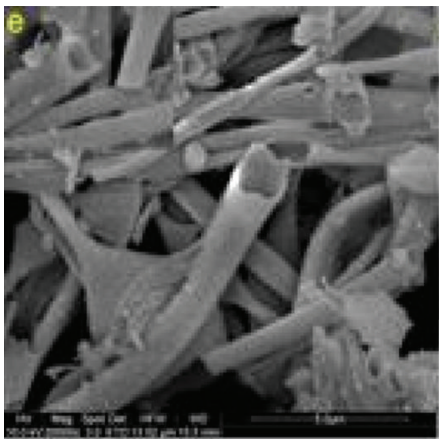

(e)

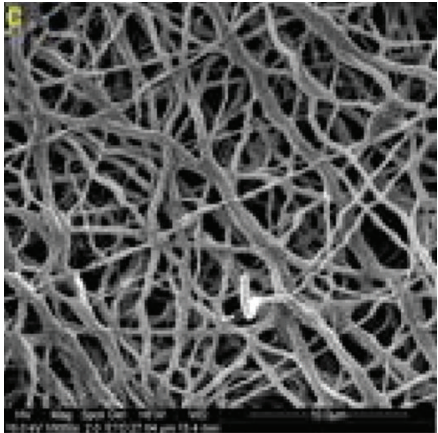

(c)

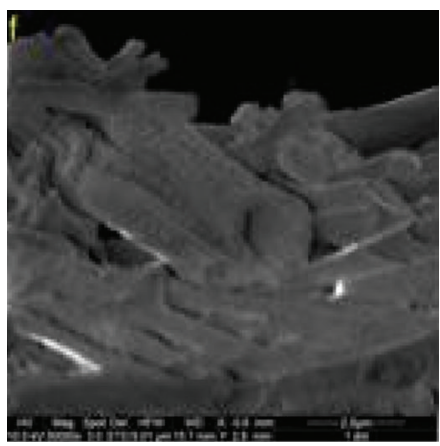

(f)

Figure 2: Micrographs showing fiber morphology (a) BTO Aligned Sintered (inset-zoom), (b) STO Aligned Sintered (inset-zoom), (c) BTO Random Sintered, (d) STO Random Sintered (inset-zoom), (e) BTO Hollow (Sonicated) (left inset-fiber), and (f) STO Hollow (Fiber).

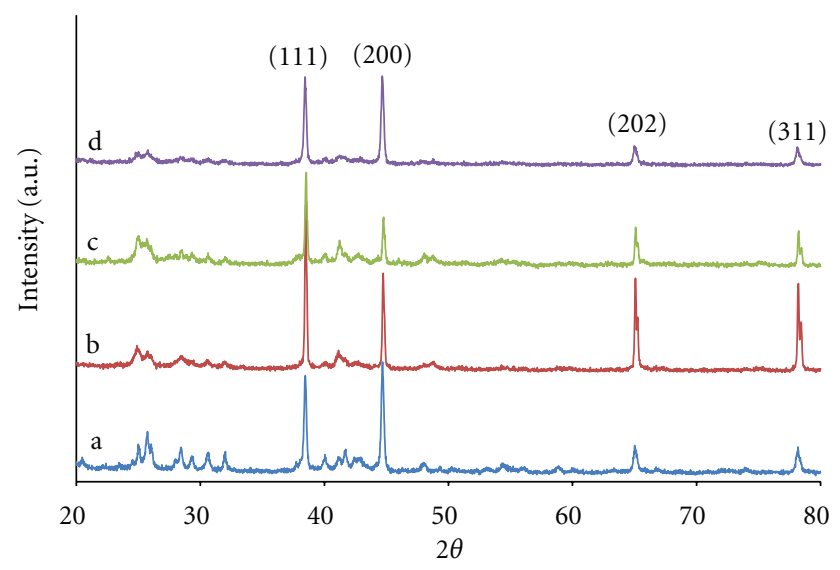

Figure 3: XRD analysis of BTO calcined at (a) $450^{\circ} \mathrm{C}$, (b) $500^{\circ} \mathrm{C}$, (c) $550^{\circ} \mathrm{C}$, and (d) $800^{\circ} \mathrm{C}$.

taken to report the average fiber diameter. Powder X-ray patterns were obtained on a Shimadzu X-ray diffractometer (Shimadzu XRD 6000, Shimadzu, Singapore) with $\mathrm{CuK} \alpha$ $(1.541 \AA)$ radiation. A JEOL 3010 HR-TEM was used to characterize the $(\mathrm{Sr} / \mathrm{Ba}) \mathrm{TiO}_{3}$ fibers and was operated at $300 \mathrm{kV}$. The $(\mathrm{Sr} / \mathrm{Ba}) \mathrm{TiO}_{3}$ fibers were dispersed in ethanol and then a drop of the above dispersion was taken on a carbon-coated copper grid (300 meshes). Absorption studies of the hollow fibers against paraoxon were done using a Unicam UV-VIS 300 series spectrophotometer with a

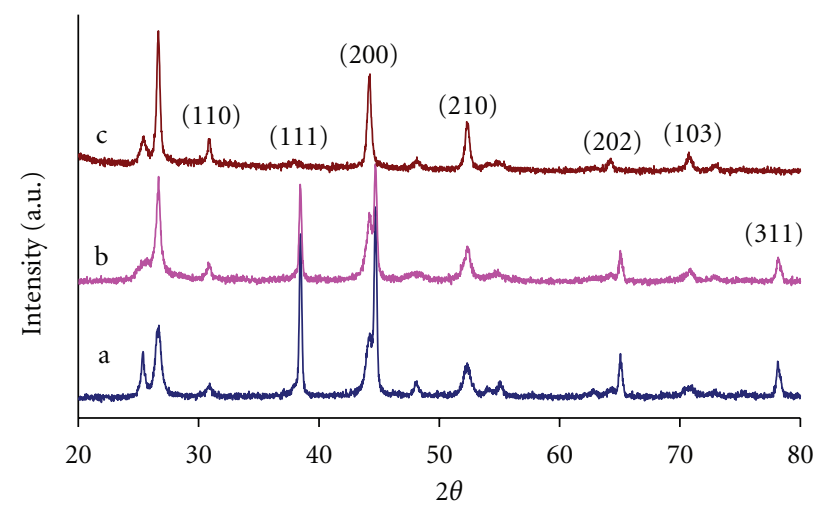

Figure 4: XRD analysis of STO calcined at (a) $500^{\circ} \mathrm{C}$, (b) $550^{\circ} \mathrm{C}$, and (c) $800^{\circ} \mathrm{C}$.

vision data system (Thermo Spectronics). BET analysis was performed for calculating the surface area of the fibers using Quantachrome Nova 2000e (Quantachrome Instruments, USA) using software Quantachrome V 11.0. UV-Vis spectra were recorded on a Thermo Spectronic Unicam UV 300 spectrophotometer. Spectra were recorded for paraoxon (or DMCP) in heptane as solvent. First, $10 \mu \mathrm{L}$ paraoxon was added to $50 \mathrm{~mL}$ heptane. To prepare a stock solution, $10 \mathrm{~mL}$ of this mixture was further diluted with $50 \mathrm{~mL}$ of heptane. To this solution, $0.5 \mathrm{~g}$ of fibers was added and the decrease in absorbance intensity at $\lambda_{\max } 268 \mathrm{~nm}$ was recorded. 


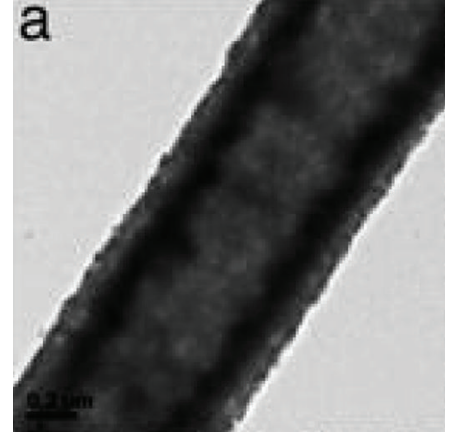

(a)

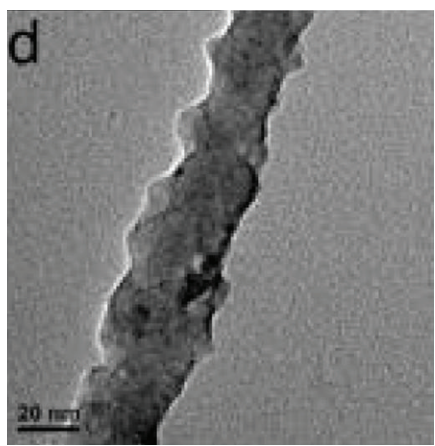

(d)

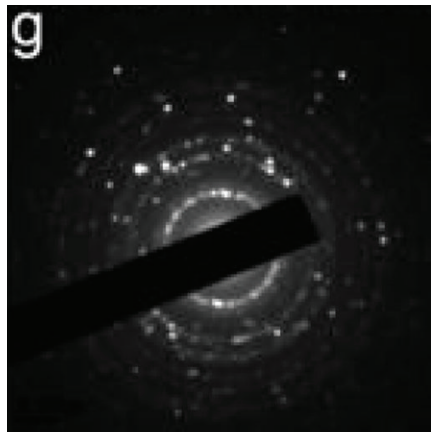

(g)

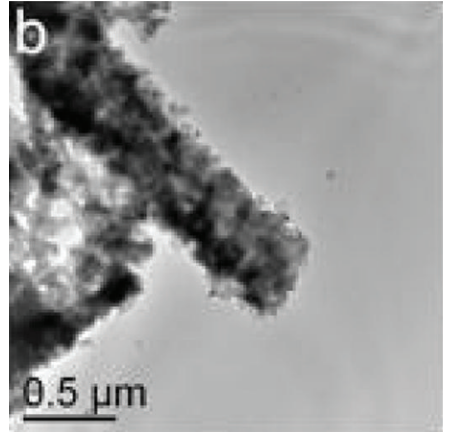

(b)

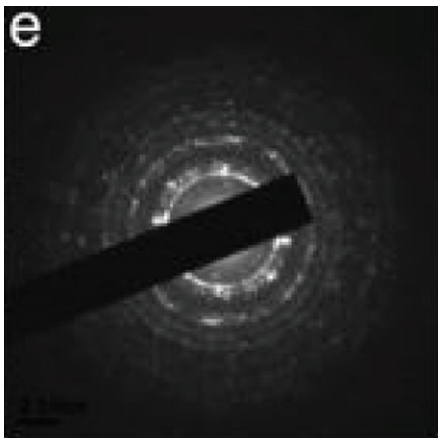

(e)

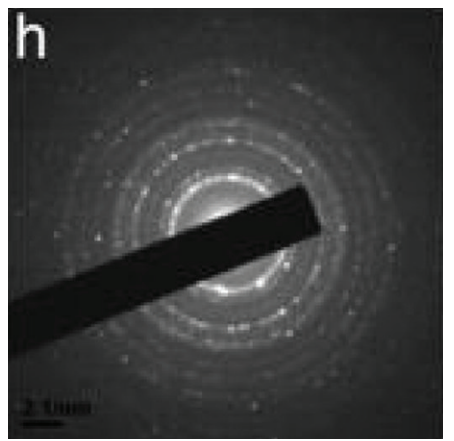

(h)

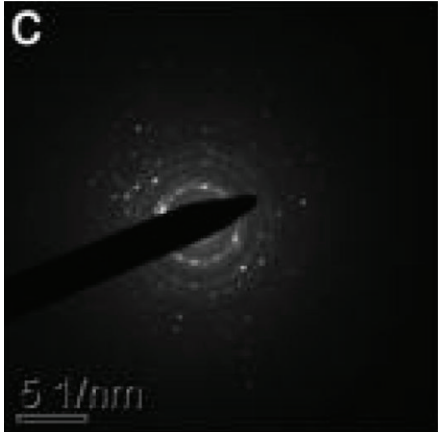

(c)

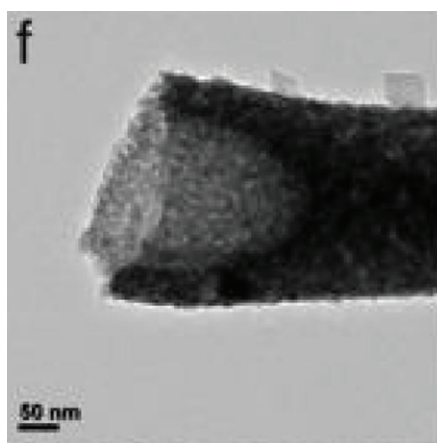

(f)

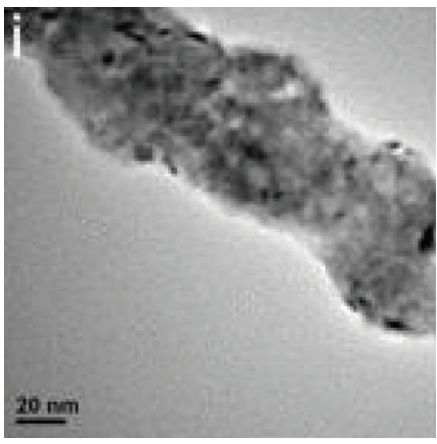

(i)

Figure 5: TEM images of (a) hollow BTO calcinated at $500^{\circ} \mathrm{C}$, (b) hollow BTO calcinated at $800^{\circ} \mathrm{C}$, (c) SAED of BTO calcinated at $500^{\circ} \mathrm{C}$, (d) solid BTO calcinated at $800^{\circ} \mathrm{C}$, (e) SAED of BTO calcinated at $800^{\circ} \mathrm{C}$, (f) hollow STO calcinated at $500^{\circ} \mathrm{C}$, (g) SAED of STO calcinated at $500^{\circ} \mathrm{C}$, (h) SAED of STO calcinated at $800^{\circ} \mathrm{C}$, and (i) solid BTO calcinated at $800^{\circ} \mathrm{C}$.

\section{Results and Discussions}

The fabrication of PVP with ultrathin uniform fibers by electrospinning method has been reported previously. It is possible to tune the fibers diameter and morphology depending on the type of organic solvent used for electrospinning process [15]. In this work, sol-gel precursors such as strontium acetate and barium acetate mixture were mixed with a PVP solution in ethanol. Titanium isopropoxide was added later to obtain the desired titanate. These precursor solutions were loaded into syringe and electrospun. After the solution had been electrospun into a thin jet, the precursors started to hydrolyze with the surrounding moisture in air and thereby generated continuous gel network within the polymer matrix. One-dimensional ceramic nanofibers were obtained by the calcinations of these composite fibers at a temperature range of $450-800^{\circ} \mathrm{C}$. The SEM images of the nanofibers are shown in Figure 2. It has been clearly observed from the SEM micrographs that the fibers are smooth and cylindrical shape in morphology. The diameters of the fibers calculated are listed in Table 1. It has been observed that the diameter varies according to the morphology of the fibers. It can be clearly seen that the solid fibers prepared are smooth and have a desirable size range (Figure 2(a)) and the aligned fibers prepared (Figure 2(b)) retain their orientation after sintering. The random fibers show similar morphology to the aligned fibers with some roughness on the surface. However, the sizes of hollow fibers were larger when compared to 
TABle 1: Variation in diameter of calcinated fibers (at $500^{\circ} \mathrm{C}$ ) according to morphology.

\begin{tabular}{lcc}
\hline Number & Type of fiber & Fiber diameter $(\mathrm{nm})$ \\
\hline 1 & Aligned calcinated STO Fibers & $85 \pm 20$ \\
2 & Random calcinated STO Fibers & $95 \pm 28$ \\
3 & Aligned calcinated BTO Fibers & $85 \pm 26$ \\
4 & Random calcinated BTO Fibers & $105 \pm 36$ \\
5 & Hollow calcinated STO Fibers & $1600 \pm 400$ \\
6 & Hollow calcinated BTO Fibers & $1600 \pm 600$ \\
\hline
\end{tabular}

solid fibers. Furthermore, a broad range of fiber diameter distribution for hollow fibers was observed. One of the possible reasons for the large size of the hollow fibers can be due to use of $1.27 \mathrm{~mm}$ needle used for shell in core-shell electrospinning, while $0.4 \mathrm{~mm}$ needle was used for the fabrication of the solid fibers. Another possible explanation could be comparatively higher concentration of the polymer solution used in core-shell electrospinning. This has resulted in the increase in the viscosity of the spinning jet during core-shell electrospinning and thereby creates higher fiber diameter.

BET analysis was performed to calculate the surface area of the fibers-a possible explanation for the difference of detoxification results among the solid and hollow fibers, since the detoxification is caused due to both chemisorption as well as physisorption. The average surface area of the solid fibers is calculated to be $\sim 8.820 \mathrm{~m}^{2} / \mathrm{g}$, whereas that of the hollow fibers is around $\sim 10.788 \mathrm{~m}^{2} / \mathrm{g}$. It is well known that the surface area of the hollow fibers is significantly much higher than that of solid fibers [16]. However, in the present study, the surface area of the hollow fibers is approximately $\sim 1.2$ times than that of the solid fibers, which is less than expected. This observed negligible or slight difference in surface area can be explained as follows: although the fibers with hollow nature is expected to contribute higher surface area, the size of the fibers (size for hollow fibers is 1-5 microns and $80-100 \mathrm{~nm}$ for solid fibers) is quite high and hence, surface area has not increased much as expected.

$\mathrm{XRD}$ analysis was performed to configure the variation in the crystallinity of BTO and STO, respectively, upon different calcination temperatures. The figures clearly show that the crystallinity of the fibers increases up to a sintering temperature of $500^{\circ} \mathrm{C}$ and then degrades gradually beyond this temperature. In the case of BTO (Figure 3), we observed the sharp and well-defined peaks formations for (111) and (200) planes corresponding to 2 theta values 38.48 and 44.74, respectively, at $500^{\circ} \mathrm{C}$. In case of STO (Figure 4), sharp peaks at 2 theta values 38.46 and 44.68 are observed corresponding to (111) and (200) planes at $500^{\circ} \mathrm{C}$. The fibers become extremely brittle, when sintered at temperatures $>700^{\circ} \mathrm{C}$, and lose their structural integrity even with the slightest contact, thus making them unusable. The XRD peaks observed in our materials are well in accordance with the reported literature [17-20].

Figure 5 shows the high-resolution TEM images of the prepared STO and BTO fibers. The surface morphology can be clearly seen in these images. The hollow fibers can

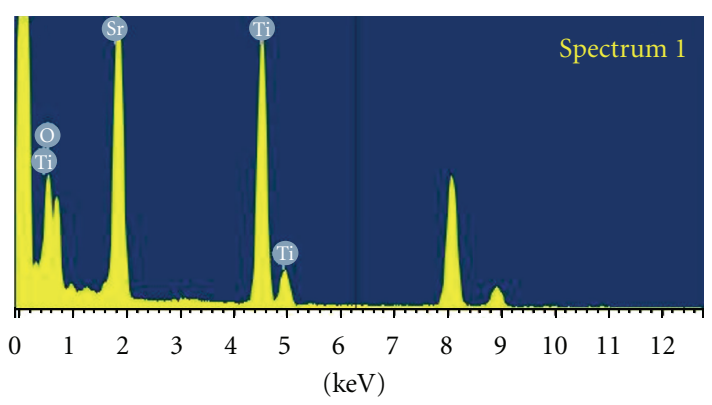

Full scale 2947 cts Cursor: 6.270 ( $43 \mathrm{cts}$ )

(a)

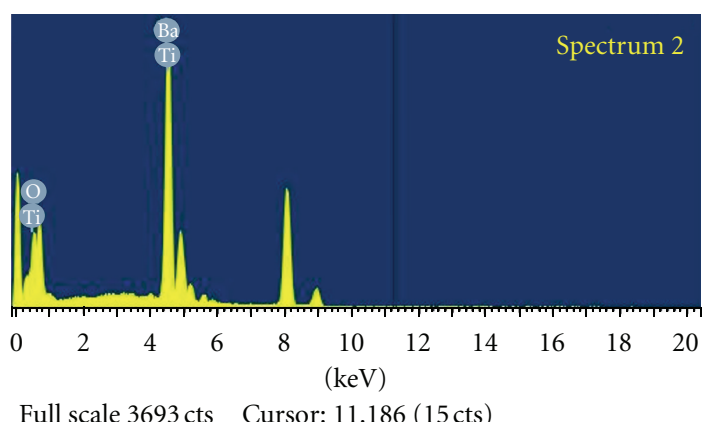

(b)

FIGURE 6: EDS of (a) strontium titanate and (b) barium titanate.

be clearly seen in Figures 5(a) and 5(f). The boundary between the interior hollow and the shell is distinct from the contrast difference (Figure 5(a)). The single area diffraction peak (SADP) also known as selected area electron diffraction (SAED) was recorded for the fibers calcinated at $500^{\circ} \mathrm{C}$ and $800^{\circ} \mathrm{C}$ (Figures 5(c), 5(e), 5(g), and 5(h)). When we compare the SAED patterns for the fibers calcined at $500^{\circ} \mathrm{C}$ with $800^{\circ} \mathrm{C}$, the bright spots (Figures $5(\mathrm{c})$ and $5(\mathrm{~g})$ ) were observed for fibers calcined at $500^{\circ} \mathrm{C}$, whereas ring patterns with faint spots were seen for the samples calcinations at $800^{\circ} \mathrm{C}$ (Figures $5(\mathrm{e})$ and $5(\mathrm{~h})$ ). This clearly indicates that better crystallinity of these materials can be obtained by calcinations at $500^{\circ} \mathrm{C}$. The SAED/SADP pattern is well in accordance with the reported literature and verifies the crystal planes determined in XRD [16].

Figures 6(a) and 6(b) show the SEM energy dispersive $\mathrm{X}$-ray spectroscopy (EDS/EDX), of the $\mathrm{SrTiO}_{3}$ and $\mathrm{BaTiO}_{3}$ calcinated at $500^{\circ} \mathrm{C}$, respectively, and indicate the presence of respective elements in the fiber. This result confirms the formation of pure $\mathrm{SrTiO}_{3}$ and $\mathrm{BaTiO}_{3}$ nanofibers. The prominent peak noticed at $8 \mathrm{keV}$ belongs to Copper $(\mathrm{Cu})$, since the samples were taken on a copper grid for analysis.

The detoxification properties of the solid and hollow fibers were compared against paraoxon-simulant for nerve agent VX using UV-vis spectroscopy. Since nerve agents are highly toxic, the simulant paraoxon is used, which has a similar structure to VX. Figure 7 shows the detoxification properties of the STO fibers with time. Similar behavior was observed for BTO fibers (not presented here). It is clearly evident that the fibers are effective in detoxifying 


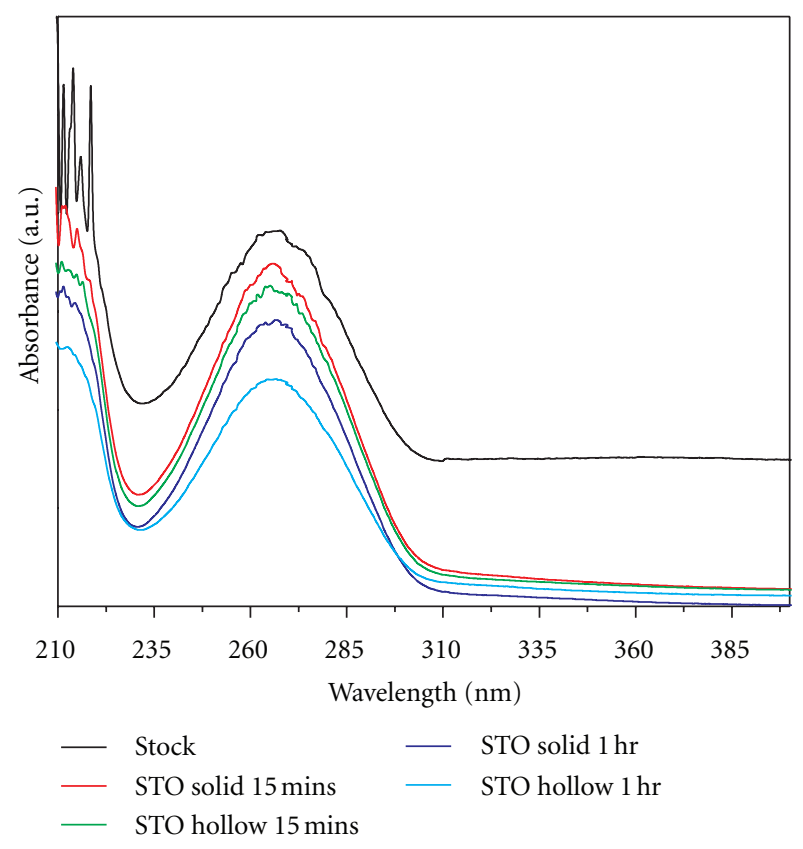

FIgURE 7: UV studies for (a) stock solution, (b) solid STO fibers 15 mins, (c) hollow STO fibers 15 mins, (d) solid STO fibers $1 \mathrm{~h}$, and (e) hollow STO fibers $1 \mathrm{~h}$.

the nerve agent simulant. The hollow fibers show better performance compared to the solid fibers. It is to be noted here that the size of the hollow fibers lies in the range of $\sim 1.5$ microns, while the solid fibers are $\sim 80-100 \mathrm{~nm}$ in size. Although the surface area of hollow fibers was 1.2 times higher than that of solid fibers, hollow fibers show better detoxification results. It is expected that the hollow fibers in the range of few nanometers will possess higher surface area and show excellent detoxification abilities. Our current aim is to bring down the size of the hollow fibers and test its properties against nerve agents as well as other harmful chemical/biological agents. This study shows that these ceramic materials can be used to decontaminate chemical and biological (CB) warfare agents and can be used as in the protection against $\mathrm{CB}$ warfare agents.

\section{Conclusions}

Electrospinning of barium titanate and strontium titanate fibers was carried out. The samples were calcinated at different temperatures and their variation in crystallinity was noted. The detoxification properties of these fibers were tested against paraoxon-simulant for nerve agent VX. It was shown that the hollow fibers perform better compared to the solid fibers, which is validated by the BET analysis. Further research is required to reduce the size of the hollow fibers to the nanometer range and evaluate its performance against various hazardous materials. We also intend to study the electrical properties of these fibers and prepare an integrated textile based on all current technology available, thereby providing a complete solution for protective clothing.

\section{Acknowledgment}

The authors gratefully acknowledge the funding support of MOE, under the Project "Green Processing of Nanofibers" under the Grant no. 265-000-318-112.

\section{References}

[1] S. W. Choi, J. Y. Park, and S. S. Kim, "Synthesis of SnO2-ZnO core-shell nanofibers via a novel two-step process and their gas sensing properties," Nanotechnology, vol. 20, no. 46, Article ID 465603, 2009.

[2] S. Ramakrishna, K. Fujihara, W. E. Teo, C. T. Lim, and Z. $\mathrm{Ma}$ :, An Introduction to Electrospinning and Nanofibers, World Scientific, Singapore, 2005.

[3] M. Cantoro, S. Hofmann, S. Pisana et al., "Effects of pretreatment and plasma enhancement on chemical vapor deposition of carbon nanotubes from ultra-thin catalyst films," Diamond and Related Materials, vol. 15, no. 4-8, pp. 10291035, 2006.

[4] R. Ramaseshan, S. Sundarrajan, R. Jose, and S. Ramakrishna, "Nanostructured ceramics by electrospinning," Journal of Applied Physics, vol. 102, no. 11, Article ID 111101, 2007.

[5] K. A. Müller and H. Burkard, " $\mathrm{SrTiO}_{3}$ : an intrinsic quantum paraelectric below 4 K," Physical Review B, vol. 19, no. 7, pp. 3593-3602, 1979.

[6] C. S. Koonce, M. L. Cohen, J. F. Schooley, W. R. Hosler, and E. R. Pfeiffer, "Superconducting transition temperatures of semiconducting $\mathrm{SrTiO}_{3}$," Physical Review, vol. 163, no. 2, pp. 380-390, 1967.

[7] K. Szot, W. Speier, G. Bihlmayer, and R. Waser, "Switching the electrical resistance of individual dislocations in singlecrystalline $\mathrm{SrTiO}_{3}$," Nature Materials, vol. 5, no. 4, pp. 312320, 2006.

[8] X. B. Yan, K. Li, J. Yin et al., "The resistive switching mechanism of $\mathrm{AgO} / \mathrm{SrTiO}_{3} / \mathrm{Pt}$ memory cells," Electrochemical and Solid-State Letters, vol. 13, no. 3, pp. H87-H89, 2010.

[9] V. K. Wadhawan, Introduction to Ferroic Materials, CRC Press, 2000.

[10] J. T. McCann, J. I. L. Chen, D. Li, Z. G. Ye, and Y. Xia, "Electrospinning of polycrystalline barium titanate nanofibers with controllable morphology and alignment," Chemical Physics Letters, vol. 424, no. 1-3, pp. 162-166, 2006.

[11] J. Yuh, L. Perez, W. M. Sigmund, and J. C. Nino, "Electrospinning of complex oxide nanofibers," Physica E, vol. 37, no. 1-2, pp. 254-259, 2007.

[12] Y. Li, X. P. Gao, G. L. Pan, T. Y. Yan, and H. Y. Zhu, "Titanate nanofiber reactivity: fabrication of $\mathrm{MTiO}_{3}(\mathrm{M}=\mathrm{Ca}, \mathrm{Sr}$, and Ba) perovskite oxides," Journal of Physical Chemistry C, vol. 113, no. 11, pp. 4386-4394, 2009.

[13] R. Ramaseshan, S. Sundarrajan, Y. Liu, R. S. Barhate, N. L. Lala, and S. Ramakrishna, "Functionalized polymer nanofibre membranes for protection from chemical warfare stimulants," Nanotechnology, vol. 17, no. 12, pp. 2947-2953, 2006.

[14] R. Ramaseshan and S. Ramakrishna, "Zinc titanate nanofibers for the detoxification of chemical warfare simulants," Journal of the American Ceramic Society, vol. 90, no. 6, pp. 1836-1842, 2007.

[15] Q. Yang, L. I. Zhenyu, Y. Hong et al., "Influence of solvents on the formation of ultrathin uniform poly(vinyl pyrrolidone) nanofibers with electrospinning," Journal of Polymer Science, Part B, vol. 42, no. 20, pp. 3721-3726, 2004. 
[16] W. S. Yun, J. J. Urban, Q. Gu, and H. Park, "Ferroelectric properties of individual barium titanate nanowires investigated by scanned probe microscopy," Nano Letters, vol. 2, no. 5, pp. 447-450, 2002.

[17] Z. Z. Lazarević, M. Vijatović, Z. Dohčević-Mitrović et al., "The characterization of the barium titanate ceramic powders prepared by the Pechini type reaction route and mechanically assisted synthesis," Journal of the European Ceramic Society, vol. 30, no. 2, pp. 623-628, 2010.

[18] Y. Hu, O. K. Tan, W. Cao, and W. Zhu, "Fabrication and characterization of nano-sized $\mathrm{SrTiO}_{3}$-based oxygen sensor for near room-temperature operation," IEEE Sensors Journal, vol. 5, no. 5, pp. 825-831, 2005.

[19] Y. Hu, O. K. Tan, W. Cao, and W. Zhu, "A low temperature nano-structured $\mathrm{SrTiO}_{3}$ thick film oxygen gas sensor," Ceramics International, vol. 30, no. 7, pp. 1819-1822, 2004.

[20] M. C. Wittels and F. A. Sherrill, "Fast neutron effects in tetragonal barium titanate," Journal of Applied Physics, vol. 28, no. 5, pp. 606-609, 1957. 

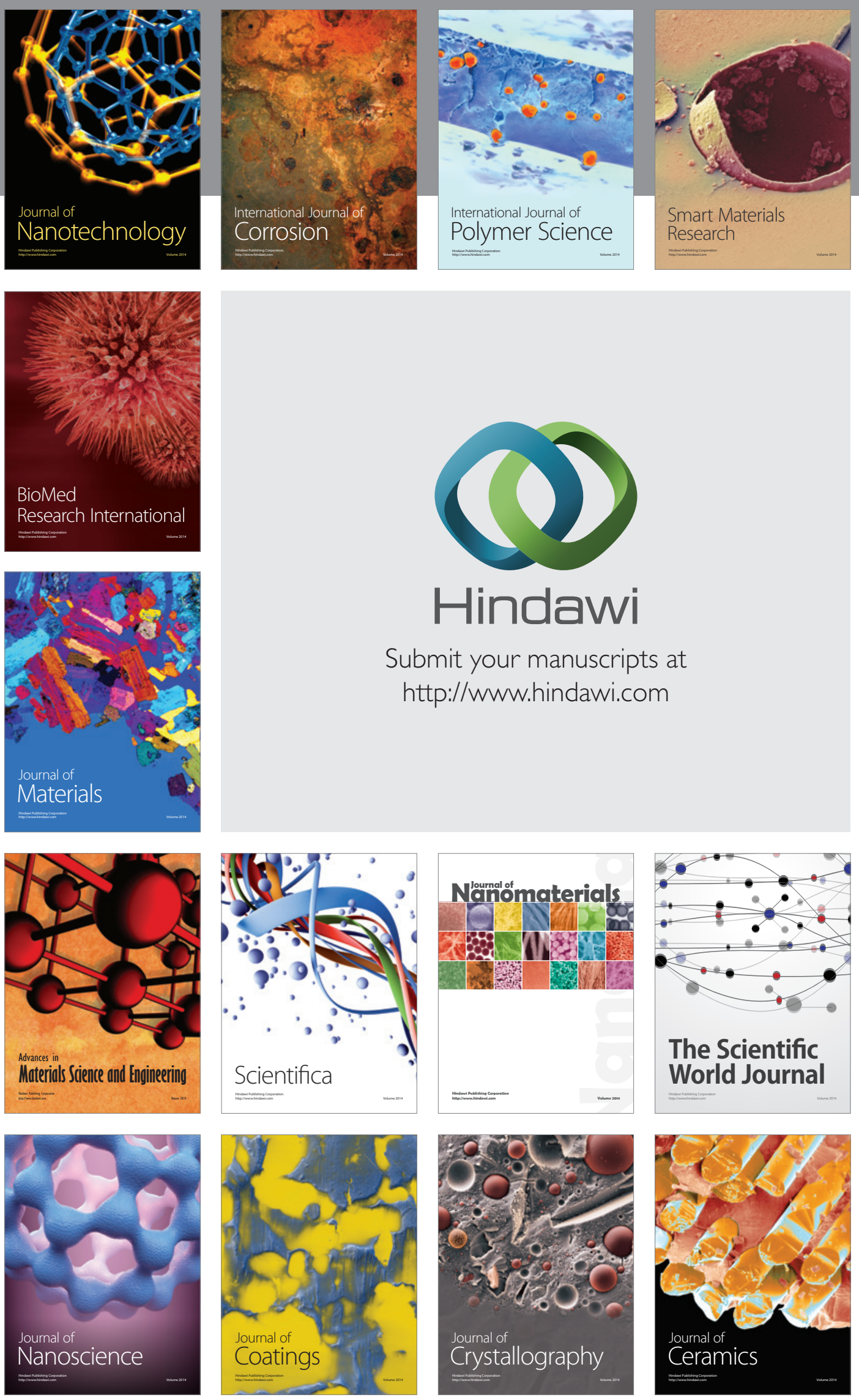

The Scientific World Journal

Submit your manuscripts at

http://www.hindawi.com

\section{World Journal}

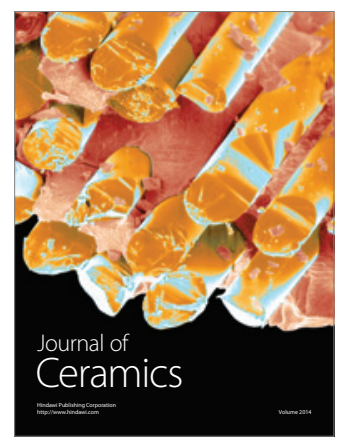

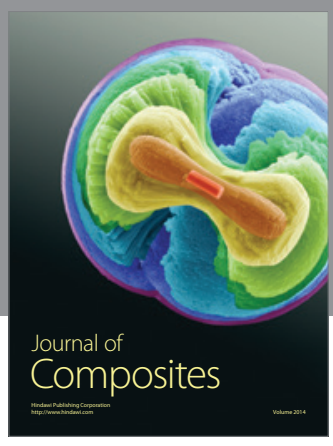
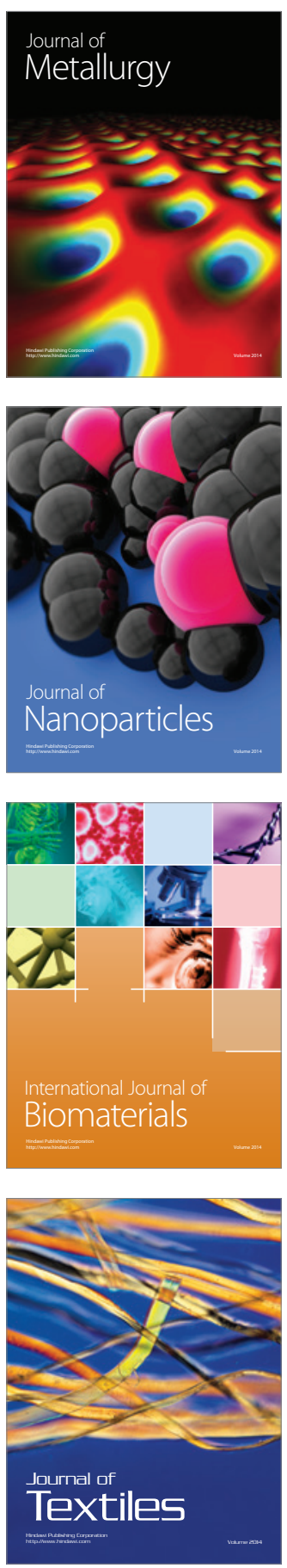